\title{
Etude à l'aide de lectines des polysaccharides pariétaux de Sphaeromonas communis
}

\author{
J Guillot'1, A Breton², M Damez¹, M Dusser'1, B Gaillard³, L Millet 3 \\ 1 Laboratoire de Botanique et Cryptogamie, Faculté de Pharmacie, Université de Clermont I, \\ 63001 Clermont-Ferrand; ${ }^{2}$ Groupe de Microbiologie, Université Clermont II, 63170 Aubière; \\ 3 INRA, Laboratoire de Microbiologie, Theix, 63122 Ceyrat, France
}

Summary - Using fluorescein isothiocyanate-labeled lectins of various specificities, differences in the cell wall polysaccharide composition among the different parts of the thallus and during the cycle of $\mathrm{S}$ communis were demonstrated.

Introduction $-S$ communis présente un cycle de développement comportant une zoospore uniflagellée dont la germination s'accompagne de la production d'une ou plusieurs vésicules homologues de rhizoïdes (Gaillard et al, 1989). Simultanément la zoospore initiale se transforme en sporange qui, à maturité, émet un grand nombre de zoospores. Nous exposons ici l'étude au moyen de lectines de la composition en polysaccharides des différentes parties du thalle de deux souches de cette espèce au cours de ce cycle.

Matériel et Méthodes - Deux souches de $S$ communis (LM16 et FG) ont été cultivées en anaérobiose pendant $48 \mathrm{~h}$ à $39^{\circ} \mathrm{C}$ sur milieu de Orpin (1975) avec et sans gélose et sur milieu semi-synthétique de Lowe et al (1985). Après centrifugation et lavage en tampon phosphate, les champignons ont été mis en contact pendant 30 min avec des lectines marquées à l'isothiocyanate de fluorescéine et de spécificités variées : Con A (Canavalia ensiformis) (-D-man/ -D-glc), LCA (Lens culinaris) (-D-man/D-glc), DSL (Datura stramonium) (D-glcNAc), LAF (Laccaria amethystina) (-L-fuc), UEA-1 (Ulex europaeus) (-L-Fuc), CGL (Clitocybe geotropa) (-Lfuc), SBA (Glycine max) (D-galNAc). La spécificité de la fixation des lectines a été vérifiée par une réaction d'inhibition à l'aide de l'ose concer- né. Les préparations ont été observées en microscopie de fluorescence.

Résultats et Discussion - Les résultats sont résumés dans le tableau I suivant, l'intensité de la fluorescence est exprimée en - (pas de fluorescence) à ++++ (fluorescence maximum).

Les résultats négatifs obtenus avec Con A et LCA indiquent l'absence d'oses de type D-glucose/D-mannose au niveau des surfaces cellulaires aux différents stades du cycle.

La fixation de la lectine du Datura (DSL) uniquement sur le sporange et les vésicules traduit la présence de chitine accessible lors de la constitution des parois. Quant à $L A F$, elle révèle l'existence de L-fucose à la surface de la spore et des vésicules alors que flagelle et sporange en sont dépourvus : l'enveloppe de la spore se modifie au cours de son évolution en sporange et une différence de structure apparaît entre le sporange et les vésicules. L'absence ou la très faible réactivité des deux autres lectines (UEA-1 et CGL), également spécifiques du L-fucose, peut s'expliquer par leur aptitude à ne reconnaître que les résidus fucosyl situés à 
Tableau I.

\begin{tabular}{|c|c|c|c|c|c|c|c|}
\hline \multirow[t]{2}{*}{ Souches } & \multicolumn{7}{|c|}{ Lectines } \\
\hline & $\operatorname{Con} A$ & $\angle C A$ & $D S L$ & LAF & UEA-1 & $C G L$ & $S B A$ \\
\hline \multicolumn{8}{|l|}{ FG } \\
\hline spore & - & - & - & +++ & _ & - & _- \\
\hline flagelle & - & - & - & - & - & - & - \\
\hline sporange & - & - & ++ & - & - & - & - \\
\hline vésicules & - & - & +++ & ++++ & + & + & ++++ \\
\hline \multicolumn{8}{|l|}{ LM16 } \\
\hline spore & - & - & - & ++ & - & - & - \\
\hline flagelle & - & _- & - & - & - & _- & - \\
\hline sporange & - & - & +++ & - & - & - & $(+)$ \\
\hline vésicules & - & - & ++++ & ++++ & - & - & ++++ \\
\hline
\end{tabular}

l'extrémité des chaînes polyosidiques; en revanche, du fait de sa faible taille (Guillot et al, 1983), LAF est capable de se fixer à des résidus latéraux moins accessibles.

La différence de structure entre les diverses parties du thalle est également démontrée par SBA qui met en évidence la présence de $\mathrm{N}$-acétyl-D-galactosamine au seul niveau des vésicules.

Les deux souches étudiées montrent un comportement sensiblement identique visà-vis des lectines, quel que soit le milieu de culture.
En conclusion, l'utilisation des lectines permet de visualiser une évolution de la composition des parois du thalle de $S \mathrm{com}$ munis au cours du cycle morphogénétique. On peut envisager cette méthode comme un moyen de détection de différences entre genres, espèces et souches.

Gaillard B, Breton A, Bernalier A (1989) Curr Microbiol 18, 83-86

Guillot J, Genaud L, Gueugnot J, Damez M (1983) Biochemistry 22, 5365-5369

Lowe SE, Theodorou MK, Trinci AP, Hespell RB (1985) J Gen Microbiol 131, 2225-2229

Orpin CG (1975) J Gen Microbiol 21, 249-262 